\title{
A Mobile-Based Intervention for Glycemic Control in Patients With Type 2 Diabetes: Retrospective, Propensity Score-Matched Cohort Study
}

Jing $\mathrm{Li}^{1 *}, \mathrm{PhD}$; Li Sun ${ }^{2 *}, \mathrm{PhD}$; Yaogang Wang ${ }^{3 *}, \mathrm{PhD} ;$ Lichuan Guo ${ }^{1}, \mathrm{MA}$; Daiqing $\mathrm{Li}^{1}, \mathrm{PhD}$; Chang Liu ${ }^{4}$, BS; Ning $\mathrm{Sun}^{5}$, MBA; Zheng $\mathrm{Xu}^{5}$, MD; Shu Li ${ }^{3}$, PhD; Yunwen Jiang ${ }^{3}$, BS; Yuan Wang ${ }^{3}$, PhD; Shunming Zhang ${ }^{3}$, MD; Liming Chen ${ }^{1}, \mathrm{PhD}$

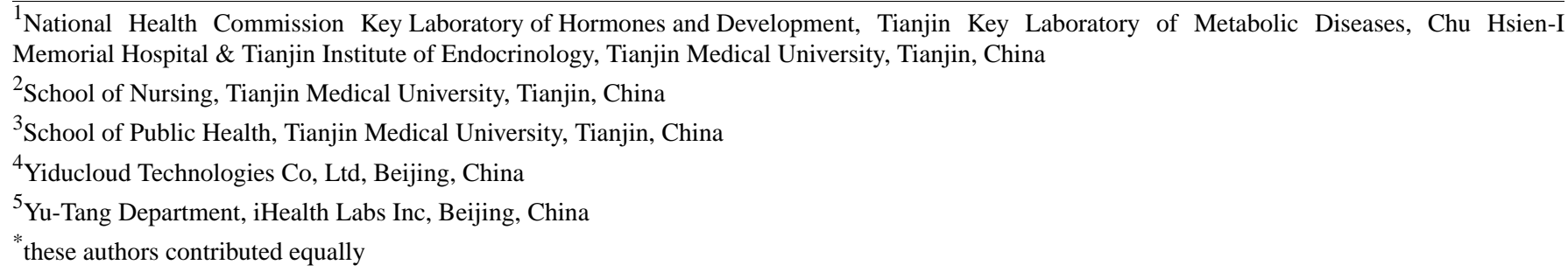

\section{Corresponding Author:}

Liming Chen, $\mathrm{PhD}$

National Health Commission Key Laboratory of Hormones and Development, Tianjin Key Laboratory of Metabolic Diseases

Chu Hsien-I Memorial Hospital \& Tianjin Institute of Endocrinology

Tianjin Medical University

No 6, Huanruibei Road, Beichen District

Tianjin, 300134

China

Phone: 8613920979401

Email: xfx22081@vip.163.com

\section{Abstract}

Background: Mobile-based interventions appear to be promising in ameliorating huge burdens experienced by patients with type 2 diabetes. However, it is unclear how effective mobile-based interventions are in glycemic management of patients with type 2 diabetes based on real-world evidence.

Objective: This study aimed to evaluate the effectiveness of a mobile-based intervention on glycemic control in patients with type 2 diabetes based on real-world population data.

Methods: This retrospective, propensity score-matched cohort study analyzed longitudinal data from a clinical electronic health database. The study population included 37,913 patients with type 2 diabetes at cohort entry between October 1, 2016, and July 31, 2018. A total of 2400 patients were matched 1:1, using propensity score matching, into the usual care and mobile health (mHealth) groups. The primary outcomes of glycemic control included control rates of glycated hemoglobin $\left(\mathrm{HbA}_{1 \mathrm{c}}\right)$, fasting blood glucose (FBG), and postprandial 2-hour blood glucose (P2BG). Mean values and variation trends of difference with 95\% CI were the secondary outcomes. The general linear model was used to calculate repeated-measures analyses of variance to examine the differences between the two groups. Subgroup and sensitivity analyses were performed.

Results: Of the 2400 patients included in the analysis, 1440 (60.00\%) were male and the mean age was 52.24 years (SD 11.56). At baseline, the control rates of $\mathrm{HbA}_{1 \mathrm{c}}, \mathrm{FBG}$, and $\mathrm{P} 2 \mathrm{BG}$ in the mHealth and usual care groups were $45.75 \%$ versus $47.00 \%$ $(P=.57), 38.03 \%$ versus $32.76 \%(P=.07)$, and $47.32 \%$ versus $47.89 \%(P=.83)$, respectively. At the 3-, 6-, 9-, and $12-\mathrm{month}$ follow-ups, the mHealth group reported higher control rates of $\mathrm{HbA}_{1 \mathrm{c}}$ than did the usual care group: 69.97\% versus $46.06 \%$ $(P<.001), 71.89 \%$ versus $61.24 \%(P=.004), 75.38 \%$ versus $53.44 \%(P<.001)$, and $72.31 \%$ versus $46.70 \%(P<.001)$, respectively. At the four follow-up sessions, the control rates of FBG in the mHealth and usual care groups were statistically different: $59.24 \%$ versus $34.21 \%(P<.001), 56.61 \%$ versus $35.14 \%(P<.001), 59.54 \%$ versus $34.99 \%(P<.001)$, and $59.77 \%$ versus $32.83 \%(P<.001)$, respectively. At the four follow-up sessions, the control rates of P2BG in the mHealth group were statistically higher than in the usual care group: $79.72 \%$ versus $48.75 \%(P<.001)$, $80.20 \%$ versus $57.45 \%(P<.001), 81.97 \%$ versus $54.07 \%(P<.001)$, and 
$76.19 \%$ versus $54.21 \%(P=.001)$, respectively. At the four follow-up sessions, the percentages of $\mathrm{HbA}_{1 \mathrm{c}}$ reduction in the mHealth group were $8.66 \%$ (95\% CI 6.69-10.63), 10.60\% (95\% CI 8.66-12.54), 10.64\% (95\% CI 8.70-12.58), and 8.11\% (95\% CI 6.08-10.14), respectively. At the four follow-up sessions, the percentages of P2BG reduction in the mHealth group were $8.44 \%$ (95\% CI 7.41-10.73), 17.77\% (95\% CI 14.98-20.23), 16.23\% (95\% CI 13.05-19.35), and 16.91\% (95\% CI 13.17-19.84), respectively. Starting from the sixth month, the mean $\mathrm{HbA}_{1 \mathrm{c}}$ and $\mathrm{P} 2 \mathrm{BG}$ values in the two groups increased slightly.

Conclusions: This mobile-based intervention delivered by a multidisciplinary team can better improve glycemic control rates of patients with type 2 diabetes than usual care. These effects were best sustained within the first 6 months. Starting from the sixth month, intensive management needs to be conducted to maintain long-term effectiveness of the mobile-based intervention.

(JMIR Mhealth Uhealth 2020;8(3):e15390) doi: $\underline{10.2196 / 15390}$

\section{KEYWORDS}

mobile health; glycemic control; type 2 diabetes; propensity score matching

\section{Introduction}

The number of adults with diabetes worldwide increased from 108 million to 422 million between 1980 and 2014 [1], with a projected increase to 642 million by 2040 [2]. In China, the overall prevalence of diabetes in the adult population was estimated to be $11.6 \%$ in 2010 and was less than $1.0 \%$ in 1980 [3]. Patients with type 2 diabetes mellitus account for $90 \%-95 \%$ of those with diabetes [4]. Diabetes not only results in blindness, cardiovascular disease, kidney failure, and other long-term consequences that substantially impact quality of life and years of life lived with disability [5,6], but also increases the risk of cancer and all-cause mortality [7-11]. Therefore, the prevention and control of diabetes is becoming more and more important.

For people with diabetes, a series of cost-effective interventions can improve their health outcomes, regardless of what type of diabetes they may have [12-17]. These interventions mainly include glycemic control, combined with diet, physical activity, and, if necessary, medication; control of blood pressure and lipids to reduce cardiovascular risk and other complications; and regular screening for damage to the eyes, kidneys, and feet to facilitate early treatment $[12,13]$. Glycemic control through quarterly physician visits with measurements of glycated hemoglobin $\left(\mathrm{HbA}_{1 \mathrm{c}}\right)$, fasting blood glucose (FBG), and postprandial 2-hour blood glucose (P2BG) were recommended in professional treatment guidelines [14]. In addition, health education, counseling, self-management, and consistent follow-up were also important for people with diabetes [15-17]. Therefore, people with diabetes require access to systematic, ongoing, and organized care delivered by a multidisciplinary team of skilled health care providers.

Mobile health (mHealth), which is defined as the use of mobile and wireless technologies for health (ie, mobile phones or sensor technologies), aims to capitalize on the rapid uptake of information and communication technologies to improve health system efficiency and health outcomes [18-20]. This includes simple apps and complex technologies, including voice, text messaging (ie, short message service), multimedia message service, Bluetooth technology, and others [21]. These advances, combined with changing patient attitudes toward self-testing, as well as an increased interest in wearable biosensors, are enticing health care providers to shift toward the paradigm of P4 medicine: predictive, pre-emptive, personalized, and participatory [22]. The characteristics of mobility, instantaneous access, and direct communication of mHealth allow for faster transfer of health information, which in turn supports patient management. mHealth is a promising tool for delivering interventions designed to promote lifestyle management of patients with type 2 diabetes. Use of mHealth often includes the possibility of sharing data between health professionals and their patients with diabetes, which could enhance the support to improve their self-management [23,24]. Successful use of mHealth technology requires an active user and cooperation among health professionals [25]. That is, the technology's effectiveness is often determined by the way in which it is provided to patients or practitioners, how it is supported or taught, and how mHealth technology is added to clinical work or daily life [26].

Previous studies have shown that mobile-based interventions developed for diabetes holistic management have some effects [23-25,27,28]. A systematic review included a meta-analysis of 14 randomized trials aiming to investigate the effect of apps on $\mathrm{HbA}_{1 \mathrm{c}}$ in the self-management of diabetes; these studies showed that the mean reduction in $\mathrm{HbA}_{1 \mathrm{c}}$ among participants using an app compared with control group participants was $0.49 \%$ (95\% CI $0.30-0.68 ; \mathrm{I}^{2}=10 \%$ ) [23]. Another systematic review of high-quality review articles and meta-analysis, which focused on utilizing technology in diabetes self-management education and support services, found that technology-enabled diabetes self-management solutions significantly improved $\mathrm{HbA}_{1 \mathrm{c}}$ and four key elements emerged as essential for improved $\mathrm{HbA}_{1 \mathrm{c}}$ : (1) communication, (2) patient-generated health data, (3) education, and (4) feedback [24]. Although the majority of these interventions showed improvement on primary endpoints $[25,27,28]$, whether results will drive substantial clinical adoption is unknown because small studies, even if randomized, are unlikely to be significantly powered to demonstrate meaningful real-world effects [20]. Therefore, real-world evidence and performance data of mobile-based interventions are needed to demonstrate value or motivate stakeholder adoption.

Based on real-world population data from a clinical electronic health database, this study aimed to evaluate the effectiveness of a mobile-based intervention on glycemic control in patients with type 2 diabetes and to explore the change in trends of glycemic parameters in the short and long term. 


\section{Methods}

\section{Study Design}

We conducted a retrospective, propensity score-matched cohort study using electronic health data from a clinical database in Tianjin, China. This clinical database was established in June 2014. The database contained longitudinal outpatient records of patients in five primary care practices and one tertiary care hospital specializing in diabetes, including their demographics, primary and secondary diagnoses, and clinical examination results.

\section{Cohort Selection}

The study cohort included 37,913 patients with type 2 diabetes who were registered in this clinical database between October 1, 2016, and July 31, 2018. The flowchart for cohort selection is shown in Figure 1.

Figure 1. Flowchart for cohort selection. GDM: gestational diabetes mellitus; T1DM: type 1 diabetes mellitus.

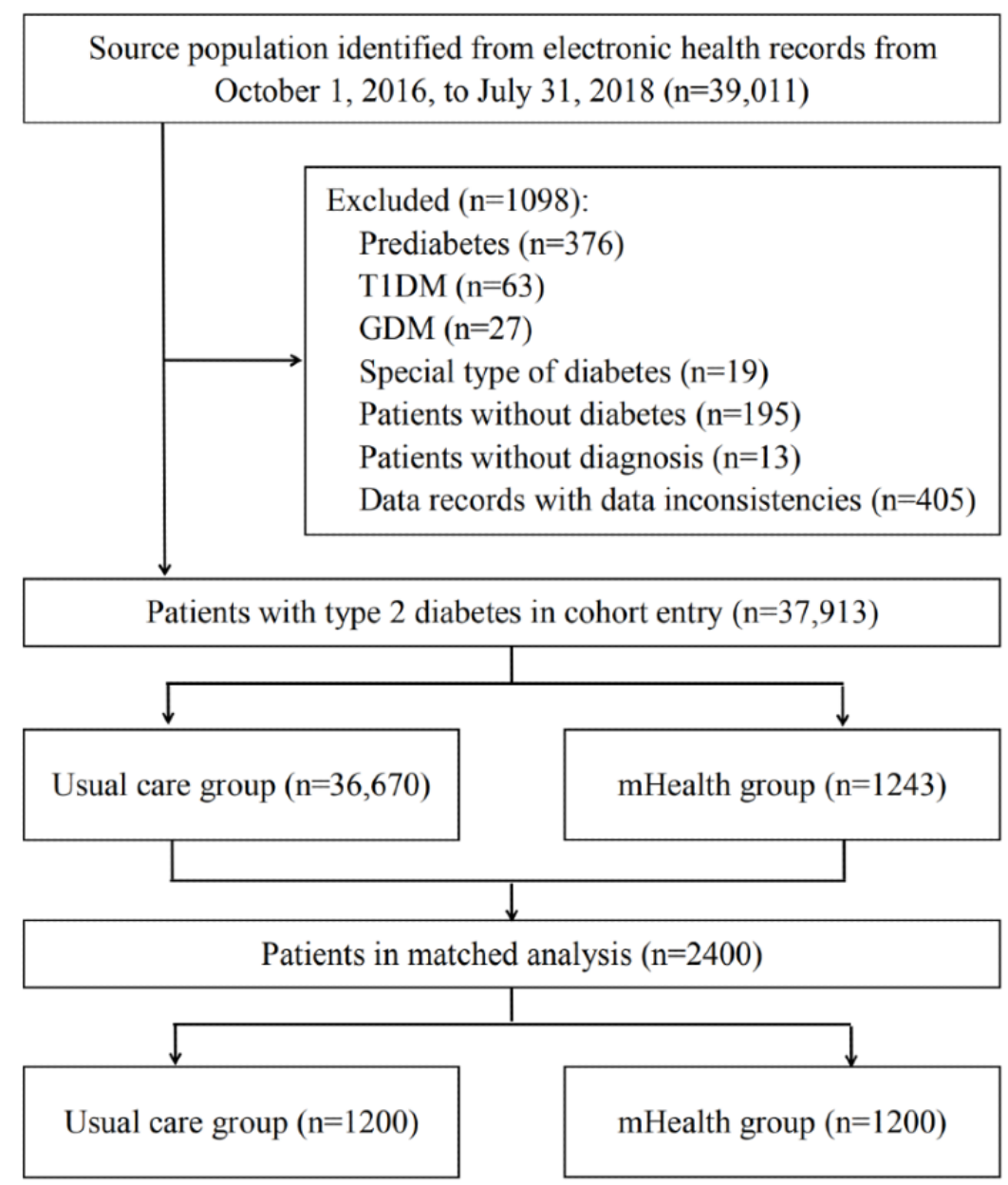

All of the patients who were registered in the clinical database between October 1, 2016, and July 31, 2018, were included in our source population. In the end, we identified 39,011 individuals with $1,793,841$ records from the clinical database. The unique ID numbers were used to identify the records of the patients with different outpatient numbers in different clinical settings. Using Microsoft Visual Basic 6.0, we developed sophisticated applications to extract and filter these data. After source population selection, the following exclusion criteria were applied: (1) prediabetes, (2) type 1 diabetes, (3) gestational diabetes, (4) special type of diabetes, (5) patients without diabetes, (6) patients without diagnosis, and (7) data records with data inconsistencies. Finally, we identified 37,913 patients with type 2 diabetes.

This unmatched cohort was divided into two groups, including the usual care group $(n=36,670)$ and the mHealth group $(n=1243)$. This was an observational study originating from the real world with no constraints on the cohort entry of participants in either group.

\section{Interventions}

The usual care group received standard medical care for patients with type 2 diabetes. Every 3 months, patients in this group underwent regular reviews to re-examine $\mathrm{HbA}_{1 \mathrm{c}}, \mathrm{FBG}$, and P2BG levels. These lab examination results were considered as evidence to support doctors' decisions to adjust medications. Meanwhile, patients in this group received routine health education at each session.

In addition to usual care, the mHealth group received a mobile-based intervention, which was continuous, real-time, personalized health care delivered by a multidisciplinary team consisting of doctors, nurses, health educators, and dietitians. 
This mobile-based intervention was based on a unified diabetes care system, which consisted of a mobile app, smart wearable medical devices (eg, wireless glucose monitor, wireless blood pressure monitor, pulse oximeter, and body composition scale), a Web platform, and a data-sharing cloud platform. Patients with type 2 diabetes in the mHealth group followed new flows in the clinical settings (see Multimedia Appendix 1). Patients' management and education in the mHealth group extended from the clinic to home. They used the wireless glucose monitors and app to perform glucose checks at home. When they experienced hypoglycemia or hyperglycemia, the app could provide tips to help them regulate their glucose levels. Patients also sent their results immediately to the support team about what to do. The care team and the service support team members would be notified when the patient was experiencing abnormal glucose levels. They then phoned the patient to inquire about their recent medication, diet, and exercise, and to help the patient in analyzing possible reasons for the abnormal glucose level. If necessary, they would invite the patient for further in-clinic consultation or guide the patient to adjust their diet or exercise by phone. Patients could also record their meals in the app and get feedback from the service support team. According to an image or a description of the food, the team would provide an overall rating of the meal, comments on portion and nutrition, and suggestions on how to do better. Patients could log their exercise type and duration into the app. The service support team created updated knowledge covering blood glucose, blood pressure, food, fitness, oral medication, insulin, psychology, and complications in the form of articles, videos, and attractive posters. Patients had access to this educational information whenever and wherever possible.

\section{Outcome Definition}

The primary outcomes were control rates of $\mathrm{HbA}_{1 \mathrm{c}}, \mathrm{FBG}$, and P2BG at baseline and at 3-, 6-, 9-, and 12-month follow-ups. We identified the control rates according to guidelines for the prevention and control of type 2 diabetes in China [29]. Control objectives were defined as follows: (1) $\mathrm{HbA}_{1 \mathrm{c}}<7 \%$, (2) 4.4 $\mathrm{mmol} / \mathrm{L}<\mathrm{FBG}<7.0 \mathrm{mmol} / \mathrm{L}$, and (3) $\mathrm{P} 2 \mathrm{BG}<10 \mathrm{mmol} / \mathrm{L}$. We also considered mean values and variation trends of difference (VTD) with $95 \% \mathrm{CI}$, separately, as secondary outcomes. The formula for calculating VTD was as follows:

$$
\mathrm{VTD}=\left(\text { Value }_{\mathrm{n}}-\text { Value }_{\text {baseline }}\right) / \text { Value }_{\text {baseline }} \times 100 \%
$$

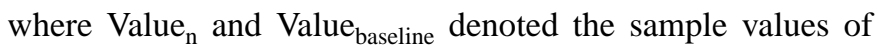
$\mathrm{HbA}_{1 \mathrm{c}}, \mathrm{FBG}$, and P2BG at $n$-month $(\mathrm{n}=3,6,9$, and 12) follow-up and baseline, respectively [30]. If VTD was positive, it represented the percentage of increase; if VTD was negative, it represented the percentage of reduction.

\section{Covariates}

Demographic and chronic disease covariates included sex, age, comorbidity (ie, hyperlipidemia and hypertension), P2BG, FBG, $\mathrm{HbA}_{1 \mathrm{c}}$, and low-density lipoprotein (LDL) cholesterol. App use-related covariates included times of FBG and P2BG self-testing, diet records, exercise records, and out-of-hospital follow-up.

\section{Statistical Analysis}

To control for the nonrandom assignment of patients, a logistic regression model that predicted the likelihood of being included in the mHealth group was constructed and used as the propensity score. Patients were then matched 1:1, using propensity score matching, into the usual care group and mHealth group. We selected all of the common available variables for two-group matching [31], including sex, age group, comorbidity (ie, hyperlipidemia and hypertension), $\mathrm{HbA}_{1 \mathrm{c}}$ level, and LDL cholesterol level. The propensity score-matching tolerance was 0.005 . No replacement was allowed, and patients were matched only once. Standardized differences with mirror histograms before and after matching are shown in Figure 2 and Multimedia Appendix 2. We evaluated the balances of matched covariates with standardized differences [29] and considered differences of less than $10 \%$ to be matched sufficiently [32,33].

We presented categorical variables as numbers (percentages) and continuous variables as means (SDs) or 95\% CIs, or as medians (IQRs), as appropriate. Descriptive statistics were used to analyze the patient demographics. Binary or categorical outcome measures were analyzed using the chi-square test and continuous measures were analyzed using the $t$ test or a nonparametric equivalent (eg, Wilcoxon rank test). We used the general linear model to calculate repeated-measures analyses of variance to examine mean differences of two groups at baseline and at 3-, 6-, 9-, and 12-month follow-ups. Subgroup analyses to explore the effects of this mobile-based intervention in different patient subgroups were undertaken for the primary and secondary outcomes. The subgroups, specified in the statistical analysis, included patient demographics: sex, age group, hyperlipidemia, and hypertension. The total proportion of missing values at the 12-month follow-up was $12.3 \%$. The proportions of missing data at each data point were $4.5 \%$ (3-month follow-up), 7.1\% (6-month follow-up), and 9.5\% (9-month follow-up). Expectation maximization was used to estimate the missing values of continuous variables. A sensitivity analysis was performed by repeating our primary analysis but excluding patients with hyperlipidemia or hypertension.

We determined statistical significance using a two-tailed $P$ value of less than .05. All of the statistical analyses were carried out using SPSS Statistics for Windows, version 25.0 (IBM Corp). 
Figure 2. Mirror histograms. (A) Before match. (B) After match.
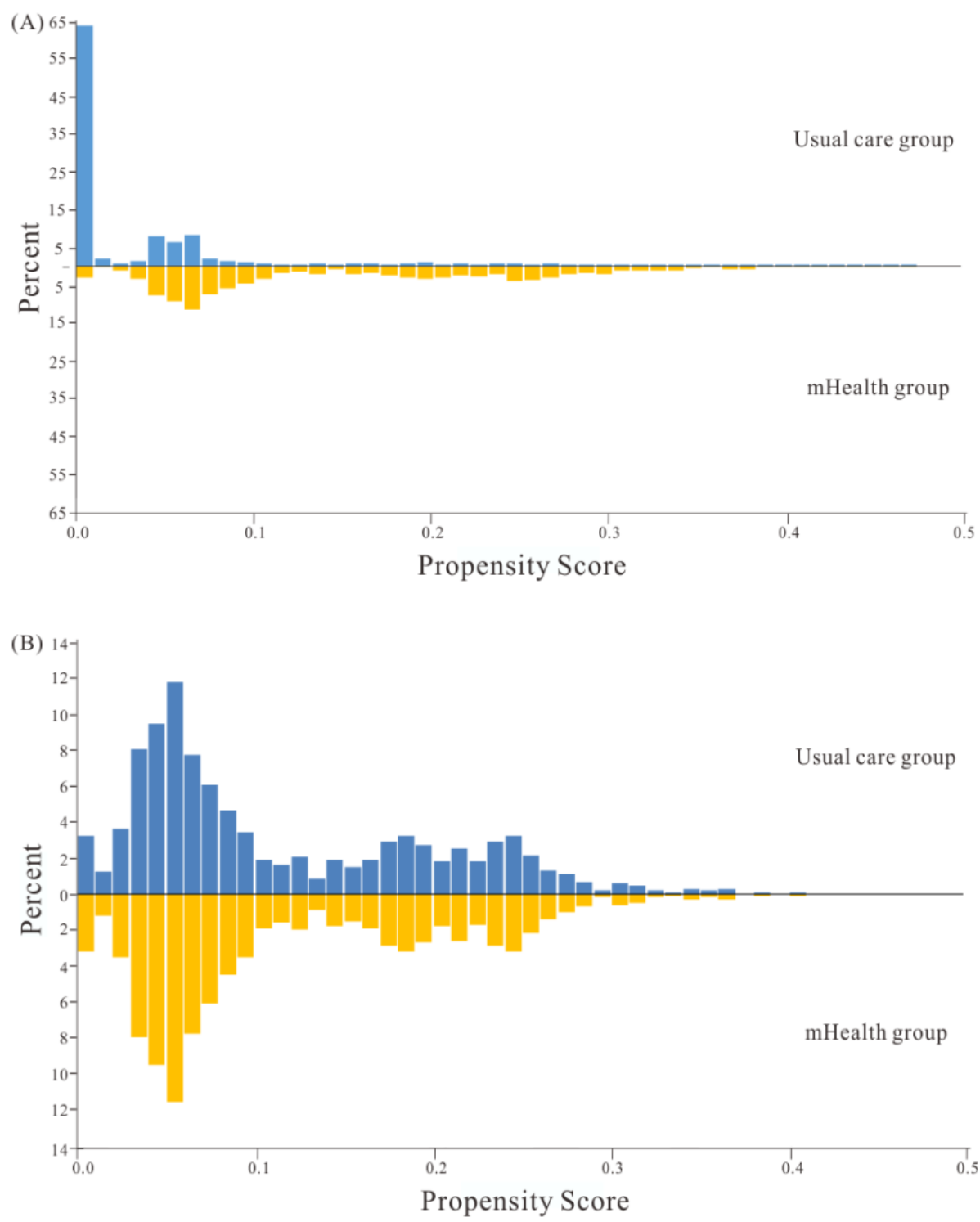

\section{Results}

\section{Patient Demographics}

Of the 39,011 patients, 37,913 met the selection criteria for additional analysis (see Figure 1). In the unmatched cohort, the proportion of male patients was $53.41 \%(20,248 / 37,913)$, patients' mean age was 57.94 years (SD 12.10), and $88.13 \%$ of patients were 36-74 years of age. The proportion of patients with hyperlipidemia was $20.52 \%(7779 / 37,913)$, and the proportion of patients with hypertension was $8.11 \%$ (3073/37,913). The mean $\mathrm{HbA}_{1 \mathrm{c}}$ level was $7.86 \%$ (SD 1.25) and the mean LDL cholesterol level was $3.37 \mathrm{mmol} / \mathrm{L}$ (SD 0.65 ). Table 1 shows the baseline demographics of patients with type 2 diabetes in unmatched and propensity score-matched cohorts. There were significant differences in demographics or glycemic parameters between the usual care group and the mHealth group.

A propensity score match was then performed and 2400 patients were matched 1:1. After matching, covariates were well balanced and we did not observe any significant differences between groups (see Table 1). In the propensity score-matched cohort, the proportion of male patients was $60.00 \%$ (1440/2400), the mean age of patients was 52.24 years (SD 11.56), and $90.13 \%$ of patients were $36-74$ years of age. A total of $48.54 \%$ $(1165 / 2400)$ of patients had a comorbidity of hyperlipidemia, and $44.38 \%$ (1065/2400) of patients had a comorbidity of hypertension. The mean $\mathrm{HbA}_{1 \mathrm{c}}$ level was 7.76\% (SD 1.39) and the mean LDL cholesterol level was $3.27 \mathrm{mmol} / \mathrm{L}$ (SD 0.79). 
Table 1. Baseline demographics of patients with type 2 diabetes in unmatched and propensity score-matched cohorts.

\begin{tabular}{|c|c|c|c|c|c|c|c|c|}
\hline \multirow[t]{2}{*}{ Characteristic } & \multicolumn{4}{|c|}{ Unmatched cohort } & \multicolumn{4}{|c|}{ Propensity score-matched cohort } \\
\hline & $\begin{array}{l}\text { mHealth group } \\
(n=1243)\end{array}$ & $\begin{array}{l}\text { Usual care group } \\
(\mathrm{n}=36,670)\end{array}$ & $P$ value & Std diff ${ }^{\mathrm{a}}$ & $\begin{array}{l}\text { mHealth } \\
\text { group } \\
(\mathrm{n}=1200)\end{array}$ & $\begin{array}{l}\text { Usual care group } \\
(n=1200)\end{array}$ & $P$ value & $\begin{array}{l}\text { Std } \\
\text { diff }\end{array}$ \\
\hline \multicolumn{9}{|l|}{$\operatorname{Sex}, \mathbf{n}(\%)$} \\
\hline Male & $777(62.51)$ & $19,471(53.10)$ & $<.001$ & 19.13 & $738(61.50)$ & $702(58.50)$ & .15 & 3.80 \\
\hline Female & $466(37.49)$ & $17,199(46.90)$ & & & $462(38.50)$ & $498(41.50)$ & & \\
\hline \multicolumn{9}{|c|}{ Age group (years), n (\%) } \\
\hline$\leq 35$ & $80(6.44)$ & $2086(5.69)$ & $<.001$ & 29.17 & $73(6.08)$ & $96(8.00)$ & .07 & 7.31 \\
\hline $36-59$ & $657(52.85)$ & $15,914(43.40)$ & & 19.10 & $631(52.58)$ & $634(52.83)$ & & 0.40 \\
\hline $60-74$ & $464(37.33)$ & $16,379(44.66)$ & & 15.10 & $454(37.84)$ & $444(37.00)$ & & 1.67 \\
\hline$\geq 75$ & $42(3.38)$ & $2291(6.25)$ & & 13.13 & $42(3.50)$ & $26(2.17)$ & & 7.78 \\
\hline \multicolumn{9}{|l|}{ Comorbidity, n (\%) } \\
\hline Hyperlipidemia & $647(52.05)$ & $7132(19.45)$ & $<.001$ & 72.67 & $604(50.33)$ & $561(46.75)$ & .09 & 7.00 \\
\hline Hypertension & $593(47.71)$ & $2480(6.76)$ & $<.001$ & 102.25 & $550(45.83)$ & $515(42.92)$ & .16 & 5.80 \\
\hline \multicolumn{9}{|c|}{ Biochemical indicator, mean (SD) } \\
\hline $\mathrm{HbA}_{1 \mathrm{c}}^{\mathrm{b}}$ level (\%) & $7.82(1.60)$ & $7.86(1.24)$ & $<.001$ & 3.16 & $7.83(1.60)$ & $7.70(1.15)$ & .26 & 9.35 \\
\hline $\begin{array}{l}\mathrm{LDL}^{\mathrm{c}} \text { cholesterol } \\
(\mathrm{mmol} / \mathrm{L})\end{array}$ & $3.26(0.88)$ & $3.38(0.64)$ & $<.001$ & 15.10 & $3.29(0.88)$ & $3.25(0.69)$ & .71 & 5.06 \\
\hline
\end{tabular}

${ }^{\text {a }}$ Std diff: standardized difference.

${ }^{\mathrm{b}} \mathrm{HbA}_{1 \mathrm{c}}$ : glycated hemoglobin.

${ }^{\mathrm{c}}$ LDL: low-density lipoprotein.

Until July 31, 2018, the total number of times of starting up the app, self-monitoring of glycemic parameters, diet recording, exercise recording, and out-of-hospital follow-ups were 80,129; 172,$355 ; 17,860 ; 4464$; and 5264 , respectively; the median follow-up time was 457 days.

\section{Control Rates of Glycemic Parameters}

At baseline, the control rates of $\mathrm{HbA}_{1 \mathrm{c}}, \mathrm{FBG}$, and $\mathrm{P} 2 \mathrm{BG}$ in the mHealth and usual care groups were $45.75 \%$ versus $47.00 \%$ $(P=.57), 38.03 \%$ versus $32.76 \%(P=.07)$, and $47.32 \%$ versus $47.89 \%(P=.83)$, respectively. The control rates of $\mathrm{HbA}_{1 \mathrm{c}}, \mathrm{FBG}$, and $\mathrm{P} 2 \mathrm{BG}$ in both groups at different follow-up sessions are shown in Figure 3.

At the 3-, 6-, 9-, and 12-month follow-ups, the mHealth group reported higher control rates of $\mathrm{HbA}_{1 \mathrm{c}}$ than usual care, which were $69.97 \%$ versus $46.06 \%$ ( $P<.001), 71.89 \%$ versus $61.24 \%$
$(P=.004), 75.38 \%$ versus $53.44 \%(P<.001)$, and $72.31 \%$ versus $46.70 \%(P<.001)$, respectively. Differences in the control rates between the two groups at these four follow-up sessions were $23.91 \%, 10.65 \%, 21.94 \%$, and $25.61 \%$, respectively. At the 9-month follow-up, the mHealth group reported the highest control rate of $\mathrm{HbA}_{1 \mathrm{c}}$, which was $75.38 \%$.

Additionally, at the 3-, 6-, 9-, and 12-month follow-ups, the control rates of FBG in the mHealth and usual care groups were statistically different, which were $59.24 \%$ versus $34.21 \%$ $(P<.001), 56.61 \%$ versus $35.14 \% \quad(P<.001), 59.54 \%$ versus $34.99 \%(P<.001)$, and $59.77 \%$ versus $32.83 \% \quad(P<.001)$, respectively. The control rates of $\mathrm{P} 2 \mathrm{BG}$ in the mHealth group were statistically higher than in the usual care group, which were $79.72 \%$ versus $48.75 \%(P<.001), 80.20 \%$ versus $57.45 \%$ $(P<.001), 81.97 \%$ versus $54.07 \%(P<.001)$, and $76.19 \%$ versus $54.21 \%(P=.001)$, respectively. 
Figure 3. Control rates of glycated hemoglobin $\left(\mathrm{HbA}_{1 \mathrm{c}}\right)$, fasting blood glucose $(\mathrm{FBG})$, and postprandial 2-hour blood glucose (P2BG) in the $\mathrm{mHealth}$ and usual care groups at different follow-up sessions.

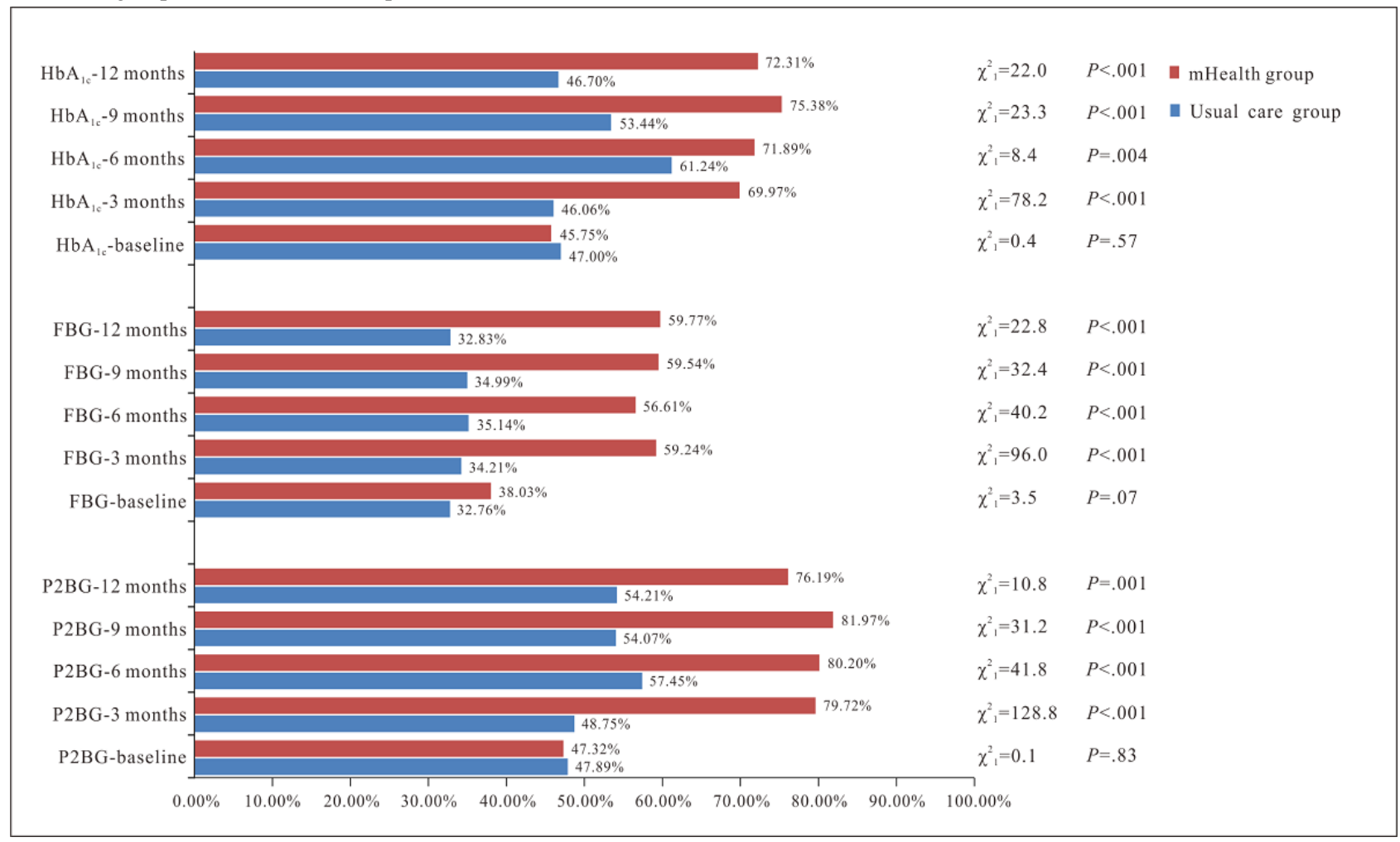

\section{Mean Values of Glycemic Parameters}

Table 2 shows the effects of this mobile-based intervention on glycemic parameters. The mean values of $\mathrm{HbA}_{1 \mathrm{c}}, \mathrm{FBG}$, and $\mathrm{P} 2 \mathrm{BG}$ in the mHealth group were significantly lower than those in the usual care group at the 3-, 6-, 9-, and 12-month follow-ups $(P<.01)$. The $P$ values of the month factor were less than .001 , which meant that the $\mathrm{HbA}_{1 \mathrm{c}}, \mathrm{FBG}$, and P2BG levels changed with time. The group and month factors had interaction effects in the mean values of $\mathrm{HbA}_{1 \mathrm{c}}, \mathrm{FBG}$, and P2BG $(P<.01)$, which meant that the effect of the time factor varied with the group. These results identified improved effects due to this mobile-based intervention on changes of the $\mathrm{HbA}_{1 \mathrm{c}}, \mathrm{FBG}$, and P2BG mean values.
Multimedia Appendices 3-7 show that, compared with usual care, at the 3-, 6-, 9-, and 12-month follow-ups, both sexes in the mHealth group reported significantly lower mean values of $\mathrm{HbA}_{1 \mathrm{c}}, \mathrm{FBG}$, and P2BG $(P<.05)$, although we did not observe any significant differences in the P2BG mean values of female participants between the two groups at the 12-month follow-up $(P=.20)$. Patients aged 36-74 years in the mHealth group had steadily lower $\mathrm{HbA}_{1 \mathrm{c}}, \mathrm{FBG}$, and P2BG mean values than those in the usual care group $(P<.05)$. No statistically significant difference was observed in $\mathrm{P} 2 \mathrm{BG}$ mean values of patients aged 36-59 years between the two groups at the 12-month follow-up $(P=.09)$. Patients younger than 35 or older than 75 years of age in the mHealth group reported unstable variation trends of mean values. 
Table 2. Effects of the mobile-based intervention on glycemic parameters.

\begin{tabular}{|c|c|c|c|c|c|c|c|c|c|c|c|}
\hline \multirow{2}{*}{$\begin{array}{l}\text { Variables and } \\
\text { group }\end{array}$} & \multicolumn{5}{|c|}{ Measurement session } & \multirow{2}{*}{$\begin{array}{l}\text { F } \\
\text { months }\end{array}$} & \multirow[t]{2}{*}{$P$ value } & \multirow{2}{*}{$\begin{array}{l}\text { F } \\
\text { groups }\end{array}$} & \multirow[t]{2}{*}{$P$ value } & \multirow{2}{*}{$\begin{array}{l}\text { F months } \\
\times \text { group }\end{array}$} & \multirow[t]{2}{*}{$P$ value } \\
\hline & Baseline & 3 months & 6 months & 9 months & $\begin{array}{l}12 \\
\text { months }\end{array}$ & & & & & & \\
\hline \multicolumn{12}{|c|}{$\mathrm{HbA}_{1 \mathrm{c}}{ }^{\mathrm{a}}(\%)$, mean $(\mathrm{SD})$} \\
\hline $\begin{array}{l}\text { mHealth } \\
\text { group }\end{array}$ & $7.83(1.60)$ & $6.70(0.73)$ & $6.60(0.61)$ & $6.44(0.59)$ & $\begin{array}{l}6.75 \\
(0.76)\end{array}$ & 11.822 & $<.001$ & 0.058 & .08 & 5.905 & .003 \\
\hline $\begin{array}{l}\text { Usual } \\
\text { care } \\
\text { group }\end{array}$ & $7.70(1.15)$ & $7.36(1.17)$ & $6.82(0.64)$ & $6.97(0.63)$ & $\begin{array}{l}7.12 \\
(0.64)\end{array}$ & & & & & & \\
\hline $\mathrm{Z}$ & -1.123 & -20.382 & -18.592 & -19.922 & -9.657 & & & & & & \\
\hline$P$ value & .26 & $<.001$ & $<.001$ & $<.001$ & $<.001$ & & & & & & \\
\hline \multicolumn{12}{|c|}{ FBG $^{\mathbf{b}}(\mathrm{mmol} / \mathrm{L})$, mean $(\mathrm{SD})$} \\
\hline $\begin{array}{l}\text { mHealth } \\
\text { group }\end{array}$ & $8.34(2.41)$ & $6.51(1.27)$ & $6.74(2.11)$ & $6.68(1.49)$ & $\begin{array}{l}6.89 \\
(1.52)\end{array}$ & 9.614 & $<.001$ & 16.425 & $<.001$ & 5.762 & $<.001$ \\
\hline $\begin{array}{l}\text { Usual } \\
\text { care } \\
\text { group }\end{array}$ & $8.68(2.34)$ & $8.53(2.37)$ & $8.45(2.45)$ & $8.38(2.39)$ & $\begin{array}{l}8.47 \\
(2.68)\end{array}$ & & & & & & \\
\hline $\mathrm{Z}$ & -1.326 & -15.268 & -17.315 & -14.831 & -5.755 & & & & & & \\
\hline$P$ value & .20 & $<.001$ & $<.001$ & $<.001$ & $<.001$ & & & & & & \\
\hline \multicolumn{12}{|c|}{ P2BG $^{c}(\mathrm{mmol} / \mathrm{L})$, mean (SD) } \\
\hline $\begin{array}{l}\text { mHealth } \\
\text { group }\end{array}$ & $\begin{array}{l}11.14 \\
(4.40)\end{array}$ & $8.03(1.75)$ & $7.75(1.90)$ & $7.89(1.77)$ & $\begin{array}{l}8.29 \\
(2.38)\end{array}$ & 12.424 & $<.001$ & 9.566 & .002 & 7.193 & $<.001$ \\
\hline $\begin{array}{l}\text { Usual } \\
\text { care } \\
\text { group }\end{array}$ & $\begin{array}{l}10.36 \\
(2.94)\end{array}$ & $9.99(2.99)$ & $9.85(2.56)$ & $9.93(2.83)$ & $\begin{array}{l}9.97 \\
(2.91)\end{array}$ & & & & & & \\
\hline $\mathrm{Z}$ & -1.575 & -23.995 & -20.921 & -16.243 & -3.149 & & & & & & \\
\hline$P$ value & .12 & $<.001$ & $<.001$ & $<.001$ & .002 & & & & & & \\
\hline
\end{tabular}

${ }^{\mathrm{a}} \mathrm{HbA}_{1 \mathrm{c}}$ : glycated hemoglobin.

${ }^{\mathrm{b}} \mathrm{FBG}$ : fasting blood glucose.

${ }^{\mathrm{c}}$ P2BG: postprandial 2-hour blood glucose.

\section{Variation Trends of Difference for Glycemic Parameters}

Figure 4 shows the variation trends of difference for glycemic parameters between the two groups. At the 3-, 6-, 9-, and 12-month follow-ups, the percentages of $\mathrm{HbA}_{1 \mathrm{c}}$ reduction in mHealth group were $8.66 \%$ (95\% CI 6.69-10.63), $10.60 \%$ (95\% CI 8.66-12.54), $10.64 \%$ (95\% CI 8.70-12.58), and $8.11 \%$ (95\% CI 6.08-10.14), respectively; the percentages of $\mathrm{P} 2 \mathrm{BG}$ reduction in the mHealth group were $8.44 \%$ (95\% CI 7.41-10.73), $17.77 \%$
(95\% CI 14.98-20.23), $16.23 \%$ (95\% CI 13.05-19.35), and $16.91 \%$ (95\% CI 13.17-19.84), respectively. Equally important was that, after 6 months, the declines in $\mathrm{HbA}_{1 \mathrm{c}}$ and P2BG of the two groups decreased, whereas the mHealth group experienced larger decreases in $\mathrm{HbA}_{1 \mathrm{c}}$ and $\mathrm{P} 2 \mathrm{BG}$ than the usual care group. At the 3-month follow-up, the reduction of FBG in the mHealth group was larger than in the usual care group $(4.83 \%$ vs $1.38 \%)$. However, starting from the sixth month, the reductions of FBG in the usual care group were larger than in the mHealth group. 
Figure 4. Variation trends of glycated hemoglobin $\left(\mathrm{HbA}_{1 \mathrm{c}}\right)$, fasting blood glucose (FBG), and postprandial 2-hour blood glucose (P2BG) differences.
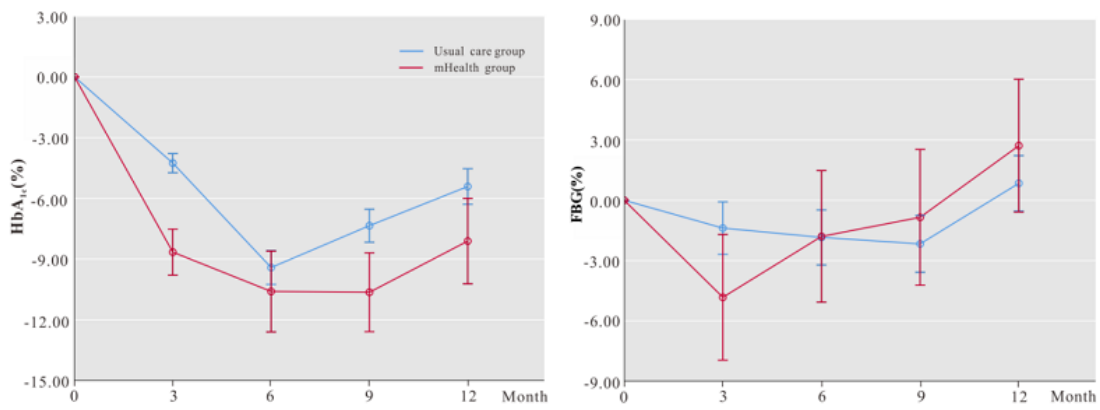

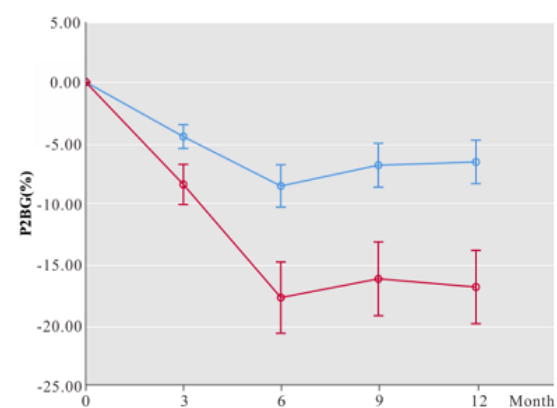

\section{Sensitivity Analysis}

We conducted sensitivity analysis, where we excluded 1587 patients with hyperlipidemia or hypertension. In the mHealth group at the baseline and the four follow-up sessions, the control rates of $\mathrm{HbA}_{1 \mathrm{c}}$ were $36.57 \%, 72.77 \%, 76.92 \%, 80.00 \%$, and $75.00 \%$, respectively; the control rates of FBG were $44.44 \%$, $65.79 \%, 65.74 \%, 59.38 \%$, and $65.63 \%$, respectively; and the control rates of $\mathrm{P} 2 \mathrm{BG}$ were $54.02 \%, 82.63 \%, 77.45 \%, 83.33 \%$, and $72.41 \%$, respectively. There were no significant differences between the sensitivity analysis and the primary analysis $\left(\chi^{2}=10.0 P=.35\right)$, so we presented only the results of the primary analysis.

\section{Discussion}

\section{Principal Findings}

In this study, a total of 2400 patients with type 2 diabetes were matched $1: 1$, using propensity score matching, into the usual care and mHealth groups. A total of $60 \%$ of the patients were male and more than half were 36-59 years of age. These demographics were similar to the population in previous studies $[29,34]$. Our results showed the improvement in control rates of $\mathrm{HbA}_{1 \mathrm{c}}, \mathrm{FBG}$, and $\mathrm{P} 2 \mathrm{BG}$ for patients with type 2 diabetes in the mHealth group compared with those in the usual care group. These effects were best sustained within the first 6 months. Starting from the sixth month, the mean $\mathrm{HbA}_{1 \mathrm{c}}$ and $\mathrm{P} 2 \mathrm{BG}$ values in the two groups increased slightly.

\section{Comparison With Prior Work}

The role of glycemic control in preventing the development and progression of complications has been proven in diabetes [35-38], with an especially strong relationship identified between intensive glycemic control and diabetic complications and mortality. In general, a target $\mathrm{HbA}_{1 \mathrm{c}}$ level of less than $7 \%$ is optimal, according to diabetes guidelines [14]. Each $1 \%$ of mean $\mathrm{HbA}_{1 \mathrm{c}}$ value reduction has been associated with a $21 \%$ reduction in the risk of diabetes-related complications [39]. A recent study on the legacy effect of early glycemic control on future complications in type 2 diabetes showed that, compared with an $\mathrm{HbA}_{1 \mathrm{c}}$ of less than $6.5 \%$ for the 0 -1-year early exposure period, $\mathrm{HbA}_{1 \mathrm{c}}$ levels of $6.5 \%$ or higher were associated with increased microvascular and macrovascular events, and $\mathrm{HbA}_{1 \mathrm{c}}$ levels of $7.0 \%$ or higher were associated with increased mortality [40]. However, a recent meta-analysis demonstrated that $\mathrm{HbA}_{1 \mathrm{c}}$ target achievement is low, with a pooled average of
$43 \%$ worldwide [41], both in primary and secondary care settings. In 2013, among Chinese patients with diabetes, only $39.7 \%$ of those treated had adequate glycemic control [34]. The reason for this low target achievement, despite the expanding arsenal of glucose-lowering interventions, remains unclear [42]. Our study found that the control rates of $\mathrm{HbA}_{1 \mathrm{c}}, \mathrm{FBG}$, and $\mathrm{P} 2 \mathrm{BG}$ in the mHealth group were higher than those in the usual care group, which were much higher than the average level worldwide [41]. These findings confirmed the effectiveness of this mobile-based intervention on glycemic control in patients with type 2 diabetes. Our study also found that at different follow-up sessions, both sexes in the mHealth group reported significantly lower mean values of $\mathrm{HbA}_{1 \mathrm{c}}, \mathrm{FBG}$, and P2BG. Patients aged 36-74 years in the mHealth group had steadily lower $\mathrm{HbA}_{1 \mathrm{c}}, \mathrm{FBG}$, and $\mathrm{P} 2 \mathrm{BG}$ mean values than those in the usual care group, and patients younger than 35 or older than 75 years old in the mHealth group reported unstable variation trends of mean values. There may be many reasons for poor glycemic control in patients older than 75 years of age in the mHealth group, including decreased self-management ability, inadequate exercise, irregular glycemic monitoring, and poor convenience in using apps, among other reasons [21,23,43]. For patients younger than 35 years old, the main reason may be poor compliance of patients and insufficient understanding of the importance of glycemic monitoring [24,25]. Especially for young patients, poor parental health literacy is the main reason $[44,45]$.

However, some studies have found that even if blood glucose is effectively controlled, the occurrence and development of complications cannot be improved or reversed [46-48]. Researchers believe that this is due to the "metabolic memory" effect of hyperglycemia [46-48]. "Metabolic memory" effect refers to the persistent damage of early hyperglycemia to tissues and organs of diabetic patients, even though the glycemic control is good [48]. A growing body of experimental evidence supports the concept that the risk for diabetes complications may be linked to oxidative stress, nonenzymatic glycosylation of proteins, epigenetic changes, and chronic inflammation, laying the foundation for the "metabolic memory" theory [46]. From a clinical standpoint, the "metabolic memory" theory supports the need for very early aggressive treatment, with the goal of normalizing metabolic control as soon as possible, especially blood glucose. Therefore, achieving glycemic control targets as soon as possible and maintaining glycemic control for a long time have significantly positive effects in the prevention of complications [14]. The treatment strategy of diabetes should 
be changed from strict glycemic control to strict glycemic control at the early stage. The mobile-based intervention in this study seems to offer a promising option to implement this strategy. One meta-analysis of 35 randomized controlled trials found that an internet-based or mobile-based intervention duration of 3 months or less yielded optimal performance [49]. Our study also found that the glycemic control rates of the mHealth group were higher than those of the usual care group at the 3-, 6-, 9-, and 12-month follow-ups. These findings were not only consistent with previous studies, but also illustrated that the mobile-based intervention had generated a statistically significant improvement on glycemic control in the short and long term $[47,49]$. Therefore, implementation of mobile-based interventions could be a promising strategy for glycemic control of patients with diabetes not only at the early stage, but also in the long term.

In our study, the mobile-based intervention was designed to provide continuous, real-time, personalized health care for patients with diabetes, and it was delivered by a multidisciplinary team consisting of doctors, nurses, health educators, and dietitians. With the help of mobile technologies, this intervention provides a solution for diabetes management that includes the following: (1) a simple and intuitive way of vital data collection, (2) automatic in-hospital exam data and at-home data consolidation, (3) convenient and timely communication with care team professionals, and (4) continuous and vivid diabetes education, both in person and through multimedia. Based on the hardware equipment and professional support team, we have realized real-time guidance and management for diabetic patients; meanwhile, we have also collected a large amount of sample data. These data from the real world reflected the effectiveness of this mobile-based intervention. Notably, we found that, starting from the sixth month, the glycemic control of patients with type 2 diabetes in the mHealth group began to fluctuate slightly. This is a reminder that intensive management needs to be conducted to maintain the long-term effectiveness of this mobile-based intervention from the sixth month.

\section{Strengths and Limitations}

A major strength of this study was the high-quality, continuously updated, clinical database of electronic medical records that provided a large sample size and reflected real-world clinical conditions. In addition, in our study, propensity score matching was used to control the confounding factors between the two groups. Propensity score matching could reduce the bias resulting from confounding variables; this approach attempted to mimic randomization by creating a sample of units that received the mobile-based intervention that is comparable, on all observed covariates, to a sample of units that received usual care.

This study had several limitations. First, as a result of its retrospective nature, we may not have addressed unobserved confounders in propensity score matching. Therefore, selection bias may exist in this research. For this reason, we used the propensity score matching to balance the common available covariates of the two groups, including sex, age, comorbidity (ie, hyperlipidemia and hypertension), $\mathrm{HbA}_{1 \mathrm{c}}$ level, and LDL cholesterol level. Second, there are inherent limitations as to what data are recorded in the clinical medical records. For instance, the clinical medical records of patients in the usual care group did not include some demographic information, such as education level, economic level, and occupation, among others, as well as anthropometry data, such as height, weight, systolic blood pressure, and diastolic blood pressure, among others. Cognitive function was not evaluated for either group. Third, in this study, the total proportion of missing values was $12.3 \%$, and the missing values were on continuous variables, including $\mathrm{HbA}_{1 \mathrm{c}}, \mathrm{FBG}, \mathrm{P} 2 \mathrm{BG}$, and LDL cholesterol. In order to decrease the amount of bias in the data, we used expectation maximization to estimate the missing values of continuous variables.

\section{Conclusions}

This mobile-based intervention delivered by a multidisciplinary team to promote glycemic control of patients with type 2 diabetes led to increases in the control rates of $\mathrm{HbA}_{1 \mathrm{c}}, \mathrm{FBG}$, and P2BG. These effects were best sustained within the first 6 months. It is noteworthy that, starting from the sixth month, intensive management might need to be conducted to maintain long-term effectiveness of this mobile-based intervention.

\section{Acknowledgments}

This work was funded by the National Natural Science Foundation of China (\#91746205 and \#71673199), the Tianjin Science and Technology Project (\#15ZXHLSY00460 and \#18ZXZNSY00280), the Natural Science Foundation of Tianjin City (\#18JCYBJC26100), and key social science projects of the Tianjin Education Commission (\#2019JWZD54).

\section{Authors' Contributions}

LC and YW (Yaogang Wang) contributed to the conception and design of the study. JL, LG, DL, CL, NS, and ZX acquired the data. JS, LS, SL, YJ, YW (Yuan Wang), and SZ analyzed the data and all authors interpreted the data. JL, LS, YW (Yaogang Wang), and LC drafted the manuscript and all authors were involved in critical revision and approval of the final manuscript. YW (Yaogang Wang) and LC contributed equally to this paper as corresponding authors. (Yaogang Wang, PhD, School of Public Health, Tianjin Medical University No 22, Qixiangtai Road, Heping District Tianjin, 300070, China, Phone: 86 13820046130, Email: wyg@tmu.edu.cn) The corresponding authors attest that all listed authors meet authorship criteria and that no others meeting the criteria have been omitted. 


\section{Conflicts of Interest}

None declared.

\section{Multimedia Appendix 1}

In-clinic user flow of the mHealth group.

[DOC File, 4589 KB-Multimedia Appendix 1]

\section{Multimedia Appendix 2}

Standardized differences before and after propensity score matching.

[DOC File, 166 KB-Multimedia Appendix 2]

\section{Multimedia Appendix 3}

Variation trends of glycated hemoglobin (HbA1c), fasting blood glucose (FBG), and postprandial 2-hour blood glucose (P2BG) mean values (sex groups).

[DOC File, 532 KB-Multimedia Appendix 3]

\section{Multimedia Appendix 4}

Variation trends of glycated hemoglobin (HbA1c), fasting blood glucose (FBG), and postprandial 2-hour blood glucose (P2BG) mean values (age groups).

[DOC File , 929 KB-Multimedia Appendix 4]

\section{Multimedia Appendix 5}

Subgroup analysis of glycated hemoglobin (HbA1c) (\%) between usual care and mHealth groups.

[DOC File, $71 \mathrm{~KB}-$ Multimedia Appendix 5]

\section{Multimedia Appendix 6}

Subgroup analysis of fasting blood glucose (FBG) (mmol/L) between usual care and mHealth groups.

[DOC File, 69 KB-Multimedia Appendix 6]

\section{Multimedia Appendix 7}

Subgroup analysis of postprandial 2-hour blood glucose (P2BG) (mmol/L) between usual care and mHealth groups. [DOC File, 69 KB-Multimedia Appendix 7]

\section{References}

1. NCD Risk Factor Collaboration (NCD-RisC). Worldwide trends in diabetes since 1980: A pooled analysis of 751 population-based studies with 4.4 million participants. Lancet 2016 Apr 09;387(10027):1513-1530 [FREE Full text] [doi: 10.1016/S0140-6736(16)00618-8] [Medline: 27061677]

2. Ogurtsova K, da Rocha Fernandes JD, Huang Y, Linnenkamp U, Guariguata L, Cho NH, et al. IDF Diabetes Atlas: Global estimates for the prevalence of diabetes for 2015 and 2040. Diabetes Res Clin Pract 2017 Jun;128:40-50. [doi: 10.1016/j.diabres.2017.03.024] [Medline: 28437734]

3. National Diabetes Research Group. A mass survey of diabetes mellitus in a population of 300,000 in 14 provinces and municipalities in China (author's transl) [Article in Chinese]. Zhonghua Nei Ke Za Zhi 1981 Nov;20(11):678-683. [Medline: 7341098]

4. American Diabetes Association. Diagnosis and classification of diabetes mellitus. Diabetes Care 2014 Jan;37 Suppl 1:S81-S90. [doi: 10.2337/dc14-S081] [Medline: 24357215]

5. The Lancet. Type 2 diabetes: The urgent need to protect young people. Lancet 2018 Dec 01;392(10162):2325. [doi: 10.1016/S0140-6736(18)33015-0] [Medline: 30527598]

6. Xu G, Liu B, Sun Y, Du Y, Snetselaar LG, Hu FB, et al. Prevalence of diagnosed type 1 and type 2 diabetes among US adults in 2016 and 2017: Population based study. BMJ 2018 Sep 04;362:k1497 [FREE Full text] [doi: 10.1136/bmj.k1497] [Medline: $\underline{30181166]}$

7. Harding JL, Shaw JE, Peeters A, Cartensen B, Magliano DJ. Cancer risk among people with type 1 and type 2 diabetes: Disentangling true associations, detection bias, and reverse causation. Diabetes Care 2015 Feb;38(2):264-270. [doi: 10.2337/dc14-1996] [Medline: 25488912] 
8. Preis SR, Hwang S, Coady S, Pencina MJ, D'Agostino RB, Savage PJ, et al. Trends in all-cause and cardiovascular disease mortality among women and men with and without diabetes mellitus in the Framingham Heart Study, 1950 to 2005. Circulation 2009 Apr 07;119(13):1728-1735 [FREE Full text] [doi: 10.1161/CIRCULATIONAHA.108.829176] [Medline: 19307472]

9. Baena-Díez JM, Peñafiel J, Subirana I, Ramos R, Elosua R, Marín-Ibañez A, FRESCO Investigators. Risk of cause-specific death in individuals with diabetes: A competing risks analysis. Diabetes Care 2016 Nov;39(11):1987-1995. [doi:

10.2337/dc16-0614] [Medline: 27493134]

10. Gregg EW, Li Y, Wang J, Burrows NR, Ali MK, Rolka D, et al. Changes in diabetes-related complications in the United States, 1990-2010. N Engl J Med 2014 Apr 17;370(16):1514-1523. [doi: 10.1056/NEJMoa1310799] [Medline: 24738668]

11. Tsilidis KK, Kasimis JC, Lopez DS, Ntzani EE, Ioannidis JP. Type 2 diabetes and cancer: Umbrella review of meta-analyses of observational studies. BMJ 2015 Jan 02;350:g7607 [FREE Full text] [doi: 10.1136/bmj.g7607] [Medline: 25555821]

12. Gaede P, Lund-Andersen H, Parving H, Pedersen O. Effect of a multifactorial intervention on mortality in type 2 diabetes. N Engl J Med 2008 Feb 07;358(6):580-591. [doi: 10.1056/NEJMoa0706245] [Medline: 18256393]

13. Wei M, Gibbons LW, Kampert JB, Nichaman MZ, Blair SN. Low cardiorespiratory fitness and physical inactivity as predictors of mortality in men with type 2 diabetes. Ann Intern Med 2000 Apr 18;132(8):605-611. [doi: 10.7326/0003-4819-132-8-200004180-00002] [Medline: 10766678]

14. Garber AJ, Abrahamson MJ, Barzilay JI, Blonde L, Bloomgarden ZT, Bush MA, et al. Consensus Statement by the American Association of Clinical Endocrinologists and American College of Endocrinology on the comprehensive type 2 diabetes management algorithm: 2019 executive summary. Endocr Pract 2019 Jan;25(1):69-100. [doi: 10.4158/CS-2018-0535] [Medline: $\underline{30742570]}$

15. Dong Y, Wang P, Dai Z, Liu K, Jin Y, Li A, et al. Increased self-care activities and glycemic control rate in relation to health education via WeChat among diabetes patients: A randomized clinical trial. Medicine (Baltimore) 2018 Dec;97(50):e13632 [FREE Full text] [doi: 10.1097/MD.0000000000013632] [Medline: 30558051]

16. Bluml BM, Kolb LE, Lipman R. Evaluating the impact of year-long, augmented diabetes self-management support. Popul Health Manag 2019 Dec;22(6):522-528 [FREE Full text] [doi: 10.1089/pop.2018.0175] [Medline: 30668228]

17. Ayre J, Bonner C, Bramwell S, McClelland S, Jayaballa R, Maberly G, et al. Factors for supporting primary care physician engagement with patient apps for type 2 diabetes self-management that link to primary care: Interview study. JMIR Mhealth Uhealth 2019 Jan 16;7(1):e11885 [FREE Full text] [doi: 10.2196/11885] [Medline: 30664468]

18. Agarwal S, LeFevre AE, Lee J, L'Engle K, Mehl G, Sinha C, WHO mHealth Technical Evidence Review Group. Guidelines for reporting of health interventions using mobile phones: Mobile health (mHealth) evidence reporting and assessment (mERA) checklist. BMJ 2016 Mar 17;352:i1174. [doi: 10.1136/bmj.i1174] [Medline: 26988021]

19. Fedele DA, Cushing CC, Fritz A, Amaro CM, Ortega A. Mobile health interventions for improving health outcomes in youth: A meta-analysis. JAMA Pediatr 2017 May 01;171(5):461-469 [FREE Full text] [doi:

10.1001/jamapediatrics.2017.0042] [Medline: 28319239]

20. Chen CE, Harrington RA, Desai SA, Mahaffey KW, Turakhia MP. Characteristics of digital health studies registered in ClinicalTrials.gov. JAMA Intern Med 2019 Jun 01;179(6):838-840. [doi: 10.1001/jamainternmed.2018.7235] [Medline: 30801617]

21. Quinn CC, Swasey KK, Torain JM, Shardell MD, Terrin ML, Barr EA, et al. An mHealth diabetes intervention for glucose control: Health care utilization analysis. JMIR Mhealth Uhealth 2018 Oct 15;6(10):e10776 [FREE Full text] [doi: 10.2196/10776] [Medline: 30322839]

22. Wood CS, Thomas MR, Budd J, Mashamba-Thompson TP, Herbst K, Pillay D, et al. Taking connected mobile-health diagnostics of infectious diseases to the field. Nature 2019 Feb;566(7745):467-474 [FREE Full text] [doi: 10.1038/s41586-019-0956-2] [Medline: 30814711]

23. Hou C, Carter B, Hewitt J, Francisa T, Mayor S. Do mobile phone applications improve glycemic control (HbA1c) in the self-management of diabetes? A systematic review, meta-analysis, and grade of 14 randomized trials. Diabetes Care 2016 Nov;39(11):2089-2095. [doi: 10.2337/dc16-0346] [Medline: 27926892]

24. Greenwood DA, Gee PM, Fatkin KJ, Peeples M. A systematic review of reviews evaluating technology-enabled diabetes self-management education and support. J Diabetes Sci Technol 2017 Sep;11(5):1015-1027 [FREE Full text] [doi: 10.1177/1932296817713506] [Medline: 28560898]

25. Garabedian LF, Ross-Degnan D, Wharam JF. Mobile phone and smartphone technologies for diabetes care and self-management. Curr Diab Rep 2015 Dec;15(12):109 [FREE Full text] [doi: 10.1007/s11892-015-0680-8] [Medline: 26458380]

26. Auerbach AD. Evaluating digital health tools: Prospective, experimental, and real world. JAMA Intern Med 2019 Jun 01;179(6):840-841. [doi: 10.1001/jamainternmed.2018.7229] [Medline: 30801610]

27. Desveaux L, Shaw J, Saragosa M, Soobiah C, Marani H, Hensel J, et al. A mobile app to improve self-management of individuals with type 2 diabetes: Qualitative realist evaluation. J Med Internet Res 2018 Mar 16;20(3):e81 [FREE Full text] [doi: 10.2196/jmir.8712] [Medline: 29549070] 
28. Hood M, Wilson R, Corsica J, Bradley L, Chirinos D, Vivo A. What do we know about mobile applications for diabetes self-management? A review of reviews. J Behav Med 2016 Dec;39(6):981-994. [doi: 10.1007/s10865-016-9765-3] [Medline: 27412774]

29. Chinese Diabetes Society. Guidelines for the prevention and control of type 2 diabetes in China (2017 Edition). Chin J Pract Intern Med 2018;38(4):292-344.

30. Austin PC. Using the standardized difference to compare the prevalence of a binary variable between two groups in observational research. Commun Stat Simul Comput 2009 Apr 09;38(6):1228-1234. [doi: 10.1080/03610910902859574]

31. Rosenbaum PR, Rubin DB. The central role of the propensity score in observational studies for causal effects. Biometrika 1983;70(1):41-55. [doi: 10.1093/biomet/70.1.41]

32. Ramos R, Comas-Cufí M, Martí-Lluch R, Balló E, Ponjoan A, Alves-Cabratosa L, et al. Statins for primary prevention of cardiovascular events and mortality in old and very old adults with and without type 2 diabetes: Retrospective cohort study. BMJ 2018 Sep 05;362:k3359 [FREE Full text] [doi: 10.1136/bmj.k3359] [Medline: 30185425]

33. Nelson DB, Rice DC, Niu J, Atay S, Vaporciyan AA, Antonoff M, et al. Long-term survival outcomes of cancer-directed surgery for malignant pleural mesothelioma: Propensity score matching analysis. J Clin Oncol 2017 Oct 10;35(29):3354-3362. [doi: 10.1200/JCO.2017.73.8401] [Medline: 28817374]

34. Xu Y, Wang L, He J, Bi Y, Li M, Wang T, 2010 China Noncommunicable Disease Surveillance Group. Prevalence and control of diabetes in Chinese adults. JAMA 2013 Sep 04;310(9):948-959. [doi: 10.1001/jama.2013.168118] [Medline: 24002281]

35. Mohan V, Mapari JA, Karnad PD, Mann JS, Maheshwari VK. Reduced diabetes mellitus-related comorbidities by regular self-monitoring of blood glucose: Economic and quality of life implications. Indian J Endocrinol Metab 2018;22(4):461-465 [FREE Full text] [doi: 10.4103/ijem.IJEM 216 17] [Medline: $\underline{30148089]}$

36. Altschul DM, Starr JM, Deary IJ. Cognitive function in early and later life is associated with blood glucose in older individuals: Analysis of the Lothian Birth Cohort of 1936. Diabetologia 2018 Sep;61(9):1946-1955 [FREE Full text] [doi: 10.1007/s00125-018-4645-8] [Medline: 29860628]

37. Nathan DM, Cleary PA, Backlund JC, Genuth SM, Lachin JM, Orchard TJ, Diabetes Control and Complications Trial/Epidemiology of Diabetes Interventions and Complications (DCCT/EDIC) Study Research Group. Intensive diabetes treatment and cardiovascular disease in patients with type 1 diabetes. N Engl J Med 2005 Dec 22;353(25):2643-2653 [FREE Full text] [doi: 10.1056/NEJMoa052187] [Medline: 16371630]

38. Liese AD, Ma X, Reid L, Sutherland MW, Bell BA, Eberth JM, et al. Health care access and glycemic control in youth and young adults with type 1 and type 2 diabetes in South Carolina. Pediatr Diabetes 2019 May;20(3):321-329. [doi: 10.1111/pedi.12822] [Medline: 30666775]

39. Stratton IM, Adler AI, Neil HA, Matthews DR, Manley SE, Cull CA, et al. Association of glycaemia with macrovascular and microvascular complications of type 2 diabetes (UKPDS 35): Prospective observational study. BMJ 2000 Aug 12;321(7258):405-412 [FREE Full text] [doi: 10.1136/bmj.321.7258.405] [Medline: 10938048]

40. Laiteerapong N, Ham SA, Gao Y, Moffet HH, Liu JY, Huang ES, et al. The legacy effect in type 2 diabetes: Impact of early glycemic control on future complications (the Diabetes \& Aging Study). Diabetes Care 2019 Mar;42(3):416-426. [doi: 10.2337/dc17-1144] [Medline: 30104301]

41. Khunti K, Ceriello A, Cos X, De Block C. Achievement of guideline targets for blood pressure, lipid, and glycaemic control in type 2 diabetes: A meta-analysis. Diabetes Res Clin Pract 2018 Mar;137:137-148. [doi: 10.1016/j.diabres.2017.12.004] [Medline: 29325774]

42. Jalving AC, Gant CM, Binnenmars SH, Soedamah-Muthu SS, Bakker SJ, Navis G, et al. Glycaemic control in the diabetes and Lifestyle Cohort Twente: A cross-sectional assessment of lifestyle and pharmacological management on HbA1c target achievement. Diabetes Obes Metab 2018 Oct;20(10):2494-2499 [FREE Full text] [doi: 10.1111/dom.13399] [Medline: 29862616]

43. Almutairi N, Hosseinzadeh H, Gopaldasani V. The effectiveness of patient activation intervention on type 2 diabetes mellitus glycemic control and self-management behaviors: A systematic review of RCTs. Prim Care Diabetes 2020 Feb;14(1):12-20. [doi: 10.1016/j.pcd.2019.08.009] [Medline: 31543458]

44. Vloemans AF, Eilander MM, Rotteveel J, Bakker-van Waarde WM, Houdijk EC, Nuboer R, et al. Youth with type 1 diabetes taking responsibility for self-management: The importance of executive functioning in achieving glycemic control: Results from the longitudinal DINO study. Diabetes Care 2019 Feb;42(2):225-231. [doi: 10.2337/dc18-1143] [Medline: 30552132]

45. Pulgarón ER, Sanders LM, Patiño-Fernandez AM, Wile D, Sanchez J, Rothman RL, et al. Glycemic control in young children with diabetes: The role of parental health literacy. Patient Educ Couns 2014 Jan;94(1):67-70 [FREE Full text] [doi: 10.1016/j.pec.2013.09.002] [Medline: 24091252]

46. Testa R, Bonfigli AR, Prattichizzo F, La Sala L, De Nigris V, Ceriello A. The "metabolic memory" theory and the early treatment of hyperglycemia in prevention of diabetic complications. Nutrients 2017 Apr 28;9(5):437 [FREE Full text] [doi: 10.3390/nu9050437] [Medline: 28452927]

47. Vervloet M, van Dijk L, de Bakker DH, Souverein PC, Santen-Reestman J, van Vlijmen B, et al. Short- and long-term effects of real-time medication monitoring with short message service (SMS) reminders for missed doses on the refill 
adherence of people with type 2 diabetes: Evidence from a randomized controlled trial. Diabet Med 2014 Jul;31(7):821-828. [doi: 10.1111/dme.12439] [Medline: 24646343]

48. Yin H, Liang S, He H, Liu XQ. Progress in therapeutic strategy for high glucose-induced metabolic memory. Prog Pharm Sci 2018;42(8):599-607.

49. Shen Y, Wang F, Zhang X, Zhu X, Sun Q, Fisher E, et al. Effectiveness of internet-based interventions on glycemic control in patients with type 2 diabetes: Meta-analysis of randomized controlled trials. J Med Internet Res 2018 May 07;20(5):e172 [FREE Full text] [doi: 10.2196/jmir.9133] [Medline: 29735475]

\section{Abbreviations}

FBG: fasting blood glucose

HbA $_{1 \mathbf{c}}$ : glycated hemoglobin

LDL: low-density lipoprotein

mHealth: mobile health

P2BG: postprandial 2-hour blood glucose

VTD: variation trends of difference

Edited by G Eysenbach; submitted 07.07.19; peer-reviewed by S Ling, Y Hong, $R$ Sun; comments to author 27.07.19; revised version received 11.09.19; accepted 09.02.20; published 11.03.20

Please cite as:

Li J, Sun L, Wang Y, Guo L, Li D, Liu C, Sun N, Xu Z, Li S, Jiang Y, Wang Y, Zhang S, Chen L

A Mobile-Based Intervention for Glycemic Control in Patients With Type 2 Diabetes: Retrospective, Propensity Score-Matched Cohort Study

JMIR Mhealth Uhealth 2020;8(3):e15390

URL: http://mhealth.jmir.org/2020/3/e15390/

doi: $10.2196 / 15390$

PMID: $\underline{32159518}$

(CJing Li, Li Sun, Yaogang Wang, Lichuan Guo, Daiqing Li, Chang Liu, Ning Sun, Zheng Xu, Shu Li, Yunwen Jiang, Yuan Wang, Shunming Zhang, Liming Chen. Originally published in JMIR mHealth and uHealth (http://mhealth.jmir.org), 11.03.2020. This is an open-access article distributed under the terms of the Creative Commons Attribution License (https://creativecommons.org/licenses/by/4.0/), which permits unrestricted use, distribution, and reproduction in any medium, provided the original work, first published in JMIR mHealth and uHealth, is properly cited. The complete bibliographic information, a link to the original publication on http://mhealth.jmir.org/, as well as this copyright and license information must be included. 